\title{
Testosterone deficiency in non-cancer opioid-treated patients
}

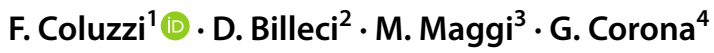

Received: 14 June 2018 / Accepted: 30 September 2018 / Published online: 20 October 2018

(c) The Author(s) 2018

\begin{abstract}
Purpose The use of opioids in patients with chronic non-cancer pain is common and can be associated with opioid-induced androgen deficiency (OPIAD) in men. This review aims to evaluate the current literature regarding the prevalence, clinical consequence and management of OPIAD.

Methods A database search was performed in Medline, Embase and Cochrane using terms such as "analgesics", "opioids" and "testosterone". Relevant literature from January 1969 to March 2018 was evaluated.

Results The prevalence of patients with OPIAD ranges from 19 to $86 \%$, depending on the criteria for diagnosis of hypogonadism. The opioid-induced suppression of gonadotropin-releasing and luteinizing hormones represents the main important pathogenetic mechanisms. OPIAD has significant negative clinical consequences on sexual function, mood, bone density and body composition. In addition, OPIAD can also impair pain control leading to hyperalgesia, which can contribute to sexual dysfunction and mood impairment.

Conclusions OPIAD is a common adverse effect of opioid treatment and contributes to sexual dysfunction, impairs pain relief and reduces overall quality of life. The evaluation of serum testosterone levels should be considered in male chronic opioid users and the decision to initiate testosterone treatment should be based on the clinical profile of individuals, in consultation with the patient.
\end{abstract}

Keywords Opioids · Chronic non-cancer pain · Opioid-induced androgen deficiency · Testosterone

\section{Introduction}

Chronic non-cancer pain (CNCP) is common worldwide, with an estimated prevalence of $8-60 \%[1,2]$, and profoundly impacts the overall quality of life and mental health of affected individuals [1,2]. CNCP is a significant economic burden for patients, health services and societies, costing an estimated $\$ 500$ billion per annum in the USA, due

G. Corona

jocorona@libero.it

1 Department of Medical and Surgical Sciences and Biotechnologies, Sapienza University of Rome, Latina, Italy

2 Neurosurgical Department, ULSS2 Treviso Hospital, University of Padua, Treviso, Italy

3 Department of Experimental and Clinical Biomedical Sciences, Sexual Medicine and Andrology Unit, University of Florence, Florence, Italy

4 Endocrinology Unit, Medical Department, Azienda Usl di Bologna, Maggiore-Bellaria Hospital, Largo Nigrisoli 2, 40133 Bologna, Italy to the impact on absenteeism and worker productivity [3]. Moreover, the burden of CNCP is expected to increase as a consequence of an aging population and increasing levels of obesity, due to lack of physical activity and urbanization [3].

Opioids are an integral part of the World Health Organization (WHO) analgesic ladder for cancer pain. In the last decade, opioids have also been widely used for CNCP; however, the epidemic of opioid overdose, recently recorded in the USA, has led to concerns about their safety [4]. Weak opioids or low doses of strong opioids may be safer than non-steroidal anti-inflammatory drugs (NSAIDs), particularly in the elderly population, as opioids do not impair organ function [5]. However, the effectiveness of opioids for long-term use in CNCP has not been established and the risk of opioid-related abuse or overdose should be avoided. Accordingly, recent guidelines from the US Centers for Disease Control and Prevention (CDC) recognize that nonopioid therapy is preferred for the treatment of CNCP [6]. Opioids should be used only when the benefits for pain and function outweigh risks [6]; this is supported by other evidence in the literature [7-9]. 
Adverse events (AEs) are common in patients treated with opioids and usually begin soon after the initiation of treatment. The most common AEs occur in the gastrointestinal tract and central nervous system (CNS), but new concerns are emerging about potential effects on bone and joint physiology [10]. Although patients develop tolerance for nausea, vomiting and CNS AEs, this is not the case for bowel dysfunction, which can persist during the entire course of treatment $[11,12]$.

The endocrine system can also be severely affected by chronic opioid treatment. Opioids can influence the secretion of hormones at different levels of the hypothalamus-pituitary-gonadal (HPG) axis [13]. Opioids generally increase the levels of growth hormone, thyroid-stimulating hormone and prolactin, but there are conflicting reports on the effects of opioids on arginine vasopressin and adrenocorticotropic hormone [13]. In addition, opioids can lead to the development of hypogonadism by directly inhibiting gonadotropinreleasing hormone $(\mathrm{GnRH})$ through the $\mu$-opioid (MOP) receptor (Fig. 1), reducing libido and causing erectile dysfunction (ED) in men, oligomenorrhea or amenorrhea in women, and bone loss or infertility in both sexes [13]. The clinical significance of opioid-induced androgen deficiency (OPIAD) and the contribution of testosterone treatment (TTh) to improve symptoms of OPIAD has not been completely clarified [14-18]. Furthermore, the role of TTh in medical conditions other than classical hypogonadism has been recently the subject of discussion [19]. The aim of this review is to evaluate the data on the prevalence of OPIAD and the risk/benefit ratio of TTh in this condition.

\section{Methods}

A comprehensive Medline, Embase and Cochrane search was performed including the following words: ("analgesics, opioid"[Pharmacological Action] OR "analgesics, opioid"[MeSH Terms] OR ("analgesics"[All Fields] AND “opioid”[All Fields]) OR “opioid analgesics"[All Fields] OR “opioid"[All Fields]) AND ("testosterone"[MeSH Terms] OR "testosterone"[All Fields]).

Publications from January 1, 1969 up to March 30, 2018 were included.

\section{Opioids and their use in CNCP}

Opioids exert their analgesic effects in humans via agonist, partial agonist or antagonist activity on opioid receptors, $\delta$ (DOP), $\kappa$ (KOP) and $\mu$ (MOP) [20]. The classical G-proteincoupled opioid receptors, known as DOP, KOP and MOP [20], are widely distributed in the CNS and to a lesser extent in the periphery [21]. Various endogenous ligands derived from pro-hormone precursors act at the receptors. Proenkephalin binds to DOP receptors and is cleaved to form metenkephalin and leu-enkephalin [22]. Dynorphin A and B, derived from prodynorphin, are agonists at the KOP receptor [23]. Proopiomelanocortin is the precursor of $\beta$-endorphin, which has agonist activity in all three opioid receptors, but principally the MOP receptor [24]. The nociceptin (NOP) receptor is a 'non-classical' G-protein-coupled receptor; its endogenous agonist is derived from a precursor compound,

Fig. 1 Summary of mechanisms involved in the pathogenesis of opioid-induced androgen deficiency. GnRH gonadotropin-releasing hormone, $F S H$ follicular-stimulating hormone, LH luteinizing hormone, $D H T$ dihydrotestosterone

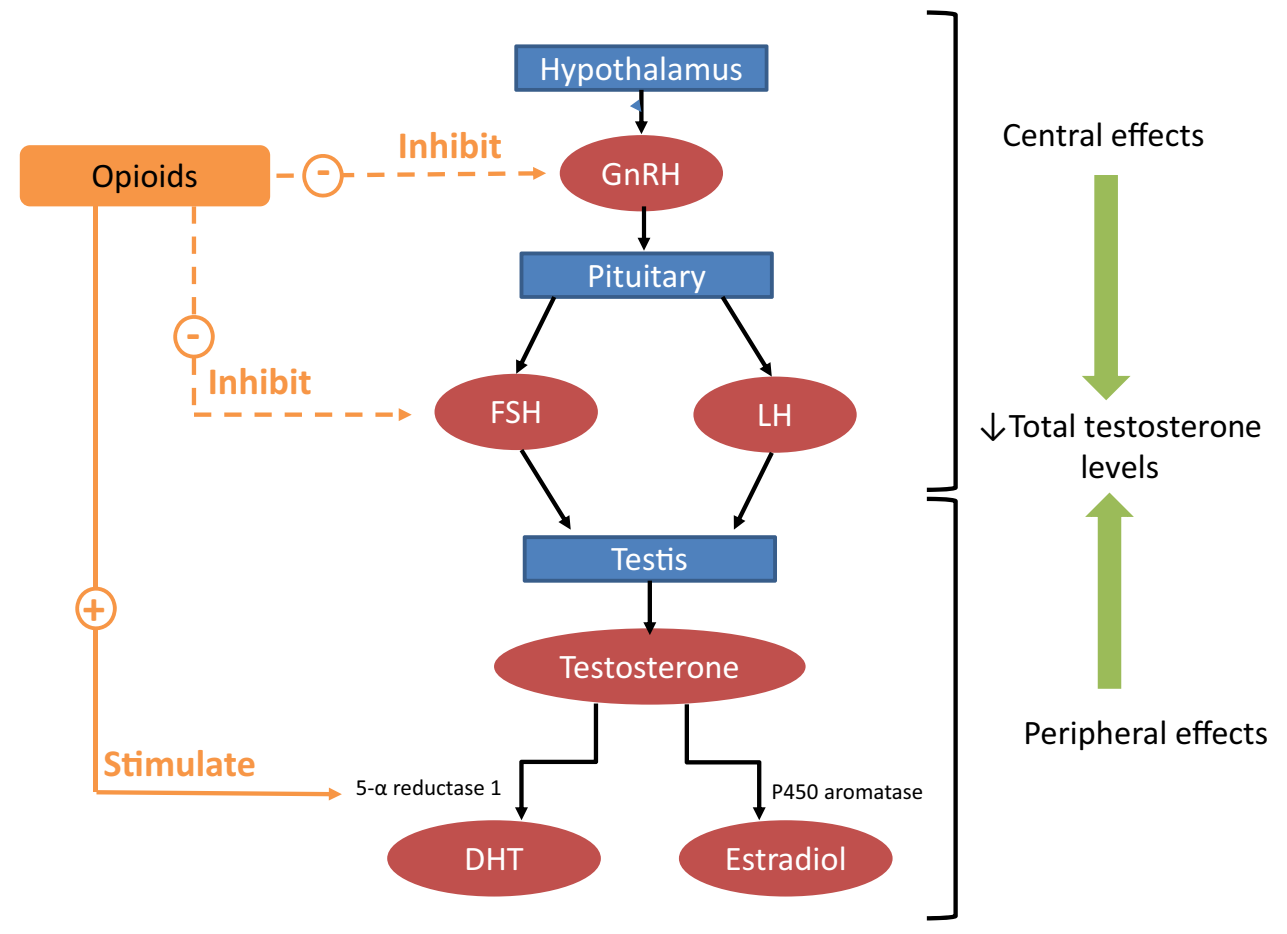


pre-pronociceptin. The NOP receptor is insensitive to the prototypical opioid agonist morphine and antagonist naloxone (Table 1).

Opioids have been widely used for CNCP, with specific recommendations about patient selection, treatment tailoring, dose titration, maintenance therapy, and tapering doses during discontinuation [25]. Despite some critical points, one in five US patients with CNCP receive prescription opioids [26]. In particular, their endocrine effects can be minimized by using drugs with a lower MOP affinity.

Opioids for CNCP are commonly classified, according to their analgesic potency, as weak (codeine and tramadol) for mild-to-moderate chronic pain, or strong opioids (morphine, oxycodone, fentanyl, hydromorphone, methadone, buprenorphine, tapentadol) for severe chronic pain. They may be also classified according to their duration of action: long-acting opioids (LAO), used to maintain a stable plasma dose during chronic therapy, short-acting opioids (SAO), mainly used for titration at the beginning of opioid therapy, and rapid-onset opioids (ROO) indicated for breakthrough cancer pain.

Codeine is a pro-drug that requires metabolic conversion to morphine for analgesic activity. A small proportion of the population $(5-10 \%)$ lacks the enzymes for this metabolic activation and as such are unable to derive pain relief from codeine (poor metabolizers) [27]. It is available in fixed combination with paracetamol (acetaminophen) for mild-tomoderate pain [28].

Tramadol is a synthetic piperidine analog of morphine. It acts as a central analgesic via MOP receptors and by modulating monoaminergic (serotonin and noradrenaline) pathways. Because its activity on the MOP receptor is significantly lower than that of morphine [29], tramadol has less potential for respiratory depression and gastrointestinal side effects [30, 31]. Tramadol is available in different formulations as SAO, LAO, and in association with paracetamol for mild-to-moderate chronic pain [32, 33].

Another weak opioid is meperidine. This agent has approximately $10 \%$ of the efficacy of morphine and a halflife of only $3 \mathrm{~h}$ after oral administration [34]. It is rapidly metabolized to normeperidine, which has a half-life of $8-12 \mathrm{~h}$ and is associated with significant CNS AEs [34].

The strong opioid morphine has been the mainstay of chronic pain management. Morphine acts as a full agonist of the MOP receptor, with weak agonist activity at DOP and KOP receptors (Table 1) [35]. It is commonly administered via the oral, intravenous, or intrathecal routes, but morphine has low lipid solubility, resulting in slow penetration through the blood-brain barrier [36]. Therefore, the onset of the analgesic effect is relatively slow and the relative hydrophilicity impairs its administration through the skin. Oral bioavailability is about $30 \%$, because morphine undergoes extensive hepatic first-pass metabolism, via glucuronidation [37]. Morphine has been shown to significantly decrease testosterone plasma levels, probably due to the action on opioid receptors present in the testis [17].

Oxycodone is a semi-synthetic derivative of thebaine with high oral bioavailability [38]. The extended-release formulations provide stable plasma levels throughout the dosing interval and allow twice-daily administration [39]. The fixed combination of oxycodone-naloxone 2:1 has significantly
Table 1 Opioid receptors with their endogenous ligands, precursors and clinical drugs with agonist or antagonist activity

\begin{tabular}{|c|c|c|c|c|}
\hline & \multicolumn{4}{|l|}{ Receptor subtype } \\
\hline & $\mathrm{DOP}(\delta)$ & KOР (к) & $\operatorname{MOP}(\mu)$ & NOP \\
\hline Precursor & Proenkephalin & Prodynorphin & Proopiomelancortin & Pre-pronociceptin \\
\hline Peptide & $\begin{array}{l}\text { Met-enkephalin, } \\
\text { leu-enkephalin }\end{array}$ & $\begin{array}{r}\text { Dynorphin A, } \\
\text { dynorphin B }\end{array}$ & $\beta$-endorphin & N/OFQ \\
\hline \multicolumn{5}{|l|}{ Agonists } \\
\hline Morphine & + & + & +++ & - \\
\hline Fentanyl & - & + & +++ & - \\
\hline Codeine & ++ & ++ & ++ & - \\
\hline Oxycodone & - & +++ & +++ & - \\
\hline Buprenorphine & - & + & ++ & + \\
\hline Tramadol & - & - & + & - \\
\hline Methadone & + & - & ++ & - \\
\hline Meperidine & + & + & ++ & - \\
\hline Tapentadol & - & + & + & - \\
\hline \multicolumn{5}{|l|}{ Antagonist } \\
\hline Naloxone & ++ & ++ & +++ & - \\
\hline
\end{tabular}

- No affinity; + low affinity; ++ intermediate affinity, +++ high affinity

N/OFQ nociception orphanin FQ, DOP delta opioid receptor, KOP kappa opioid receptor, $M O P$ mu opioid receptor, $N O P$ nociceptin opioid receptor 
improved the gastrointestinal tolerability of oxycodone, reducing the incidence of opioid-induced bowel dysfunction [40]. However, when administered in males, oxycodone significantly reduces testosterone levels; in one study, $45.5 \%$ of patients treated with oxycodone (mean $75 \mathrm{mg} /$ day) had testosterone values below the normal reference range after 12 weeks of treatment [41].

Hydromorphone is available for chronic pain management as a once-daily formulation, using an osmotic-controlled-release oral delivery system $\left(\mathrm{OROS}^{\circledR}\right)$. This formulation is minimally affected by food or alcohol, provides stable plasma concentrations and enhances patient adherence to treatment by reducing dosing frequency [42].

Fentanyl is a synthetic opioid analgesic with high lipid solubility and a faster onset of action than morphine [43]. All ROOs are fentanyl based, but their use is not indicated for CNCP. In chronic pain management, fentanyl is mainly used in transdermal formulations. Compared with oral opioids, transdermal fentanyl is associated with a lower incidence of side effects (constipation, nausea and vomiting, and daytime drowsiness), increased patient satisfaction and quality of life, and improved compliance resulting from administration every $72 \mathrm{~h}$ [44]. However, the convenience of the fentanyl patch should be weighed against the highest risk of androgen deficiency, when compared with other commonly prescribed opioids [45].

The "atypical opioid" tapentadol has a pharmacological profile that is distinct from all other opioids. It has a dual mechanism of action: $\mu$-opioid receptor agonist/noradrenaline reuptake inhibitor (MOR/NRI). The affinity of tapentadol for the MOP receptor is 50 times lower than that of morphine, which, when counterbalanced by its activity on noradrenaline modulation, results in an improved tolerability profile, lower rate of tolerance development, lower abuse potential, and efficacy in both nociceptive and neuropathic pain $[46,47]$. Tapentadol has been mainly studied in CNCP, including low back pain (LBP), neck pain, osteoarthritis, and painful diabetic peripheral neuropathy [48-50]. Compared with oxycodone/naloxone, tapentadol at the mean dosage of about $378 \mathrm{mg} /$ day had minimal or no significant effects on testosterone levels in male patients with severe chronic LBP [41], probably related to the dual mechanism of action [51].

Buprenorphine also differs from traditional opioids (pure MOP agonists), because it works as a non-selective partial opioid agonist. It produces analgesic effects via MOP receptors and also antagonizes morphine antinociception at high doses via interaction with the KOP and NOP receptors [52]. Furthermore, compared with pure MOP agonists, buprenorphine has reduced potential for respiratory depression, overdose, and abuse, making it a useful drug for patients with chronic pain. At low dosages, transdermal buprenorphine is an accepted around-the-clock pain reliever for mild-to-moderate chronic pain [53]. Unlike morphine, buprenorphine has only limited endocrine effects and can be used for months without inducing hypogonadism [17].

Methadone is a synthetically derived opioid with agonist affinity for both the MOP and DOP receptors. Methadone has improved safety and tolerability compared with morphine because of its lower affinity for the MOP receptor. Methadone is mainly used in patients with chronic cancer pain who have reached a high opioid dose or in patients with a history of substance abuse as part of a methadone maintenance program (MMT) [54]. In these patients using high-dose MMT, low serum testosterone levels have been reported: the percentage of hypogonadism in men reached $75 \%$, while in women was only $21 \%$ [55].

\section{Opioid-induced androgen deficiency}

\section{Prevalence}

The association between reduced testosterone levels, androgen deficiency and opioid treatment has been documented since the 1970s, when reports emerged in men who were on maintenance methadone therapy [56, 57]. Since then, several studies with a limited number of patients have also suggested an association between testosterone suppression and opioid treatment [16-18]. A meta-analysis performed in 2015, including 17 studies and 800 opioid users and 1969 controls, concluded that mean testosterone levels were significantly lower in men treated with opioids compared with controls [58]. However, the analysis included a heterogeneous group of studies in men treated with opioids for different reasons. This represents an important limitation because comorbidities can profoundly influence testosterone levels. Addictive disorders, such as alcohol or opioid dependence, are frequently associated with human immunodeficiency virus (HIV) and chronic hepatitis, which can affect testosterone metabolism through direct (hepatic impairment) and indirect (use of retroviral drugs) mechanisms [59-61].

Studies evaluating the impact of opioid treatment on testosterone levels in men with CNCP show that the prevalence of OPIAD ranges from 19 to $86 \%$, depending on the testosterone threshold used to define hypogonadism (Table 2) [45, 55, 62-72]. While OPIAD definitions vary, most studies report an overall prevalence higher than 50\%, confirming the significant impact of opioids in reducing testosterone levels. Although few studies have investigated the impact of opioid dosage or specific drug characteristics on testosterone levels, the available evidence suggests an increased risk of androgen deficiency with higher opioid doses and with SAO than LAO formulations. However, in equivalent doses, LAOs are significantly more likely than SAOs to cause androgen deficiency in men [69]. Doses exceeding approximately $100 \mathrm{mg}$ of oral morphine 
Table 2 Summary of the literature evaluating the impact of opioid treatment on testosterone levels in men with non-cancer pain

\begin{tabular}{|c|c|c|c|c|c|c|c|c|}
\hline Publication & Study design & $N$ & Age (years) & $\begin{array}{l}\text { Type of opioid/ } \\
\text { route of adminis- } \\
\text { tration }\end{array}$ & MSE (mg) & $\begin{array}{l}\text { Mean testoster- } \\
\text { one level during } \\
\text { opioids (nmol/L) }\end{array}$ & $\begin{array}{l}\text { Testosterone } \\
\text { threshold } \\
\text { for defining } \\
\text { hypogonadism } \\
(\mathrm{nmol} / \mathrm{L})\end{array}$ & $\begin{array}{l}\text { Proportion with } \\
\text { hypogonadism } \\
(\%)\end{array}$ \\
\hline Abs et al. [62] & Cohort & 29 & 48.4 & $\begin{array}{l}\text { Morphine/ } \\
\text { intrathecal }\end{array}$ & 4.8 & 6.8 & 9.0 & 86.2 \\
\hline Finch et al. [63] & Cross-sectional & 11 & 46.5 & $\begin{array}{l}\text { Morphine/ } \\
\text { intrathecal }\end{array}$ & $0.5-40$ & 4.8 & 10.0 & 100 \\
\hline Daniell et al. [64] & Cross-sectional & 23 & 49.4 & Mixed/oral & $70-120$ & 6.5 & NR & 74.0 \\
\hline $\begin{array}{l}\text { Roberts et al. } \\
\text { [65] }\end{array}$ & Cohort & 10 & 52.4 & $\begin{array}{l}\text { Mixed/oral or } \\
\text { intrathecal }\end{array}$ & 3.3 & 3.9 & 10.0 & 100 \\
\hline $\begin{array}{l}\text { Rajagopal et al. } \\
\text { [66] }\end{array}$ & Cross-sectional & 20 & 50.1 & Mixed/oral & $>200$ & 3.9 & 8.3 & 90 \\
\hline Fraser et al. [55] & Cross-sectional & 12 & 45.4 & $\begin{array}{l}\text { Mixed/oral or } \\
\text { transdermal }\end{array}$ & 718 & 6.9 & $\begin{array}{l}\text { Age specific } \\
\text { range }\end{array}$ & 83 \\
\hline Duarte et al. [67] & Cross-sectional & 20 & 58.0 & $\begin{array}{l}\text { Morphine/ } \\
\text { intrathecal }\end{array}$ & 2.68 & 4.9 & 8 & 85 \\
\hline $\begin{array}{l}\text { Rubinstein et al. } \\
\text { [68] }\end{array}$ & Cross-sectional & 81 & $26-79$ & Mixed/oral & 184 & NR & 8.6 & 53 \\
\hline Kim et al. [72] & Cross-sectional & 8 & 60.1 & Intrathecal & 12.3 & 9.1 & NR & 50 \\
\hline $\begin{array}{l}\text { Rubinstein et al. } \\
\text { [69] }\end{array}$ & Cross-sectional & 1585 & 54.0 & Mixed/oral & 76 & NR & 8.6 & 43.6 \\
\hline Cepeda et al. [71] & Cross-sectional & 146 & 49.1 & Mixed/oral & NR & 11.8 & 10 & 35.1 \\
\hline Ajo et al. [70] & Cross-sectional & 120 & 58.4 & Mixed/oral & 77 & NR & 10 & 19 \\
\hline $\begin{array}{l}\text { Rubinstein et al. } \\
\text { [45] }\end{array}$ & Cross-sectional & 1159 & 53.1 & Mixed/oral & 44 & 9.9 & 8.6 & 38.9 \\
\hline
\end{tabular}

$M S E$ morphine sulfate equivalent, $N R$ not reported

equivalent may be more likely to trigger the onset of OPIAD, compared with lower opioid doses [73], although this finding has not been confirmed by other researchers $[56,65]$. In a more recent study comparing different opioid formulations, neither the chemical structure nor the lipophilicity of the opioid explained the androgen suppression [45]. Certain opioids are associated with an increased risk of androgen deficiency. In particular, the risk of androgen deficiency is highest with fentanyl, followed by methadone and oxycodone [45]. Tapentadol, which has a 50-fold lower affinity for the human MOP receptor than morphine, has a lower impact on sex hormone concentrations, compared with pure opioid analgesics, supporting the role of MOP receptors in the pathogenesis of OPIAD [41, 74]. In randomized, comparative studies, morphine and controlled-release oxycodone reduced serum testosterone levels to a greater extent than extended-release tapentadol $[41,74]$. The presence of comorbidities, particularly diabetes, hypertension and dyslipidemia, further increases the risk of OPIAD [45]. This is not surprising as several studies have documented the influence of metabolic diseases on different levels of the hypothalamus-pituitary-testis axis and testosterone production [75-78].

\section{Pathophysiology}

Animal studies The primary mechanism by which opioids affect testosterone production is by inhibiting the secretion of GnRH (Fig. 1) [12]. Injections of $\beta$-endorphin in the ventromedial, anterior and preoptic-septal hypothalamic areas decrease the secretion of luteinizing hormone ( $\mathrm{LH}$ ) from the pituitary [79]. Li and Pelletier [80] used in situ hybridization to demonstrate that morphine down-regulates $\mathrm{GnRH}$ mRNA levels. Accordingly, chronic morphine administration inhibits GnRH secretion [13]. However, follicle-stimulating hormone (FSH) levels are not affected by opioid analogs or antagonists [13]. Animal models have also shown that opioids can modulate the negative feedback of sex steroids on LH secretion [13]. In male rats, morphine enhances the sensitivity of the hypothalamus to negative feedback by testosterone [81]. Lastly, there is a possibility that opioids can also influence peripheral testosterone metabolism. In a rat model, morphine administration increased the expression of 5- $\alpha$ reductase type 1 and/or P450-aromatase mRNA in different body regions (Fig. 1) [82].

Human studies The available data on the OPIAD mechanism in humans reflects the findings of animal models 
(Fig. 1) [13]. In healthy, adult men, morphine decreases LH pulse frequency, but does not affect FSH levels [13]. It was suggested that treatment with opioids impairs gonadotropin pulse amplitude or affects the response of the anterior pituitary to $\mathrm{GnRH}$, leading to a decrease in testosterone levels [83]. Interestingly, the effect of opioids on the human hypothalamus-pituitary-testis axis differs according to pubertal stage [13]. For example, naloxone administration failed to increase LH levels in early puberty, whereas it had a stimulatory effect in late pubertal boys [84], suggesting that regulation of central opioid receptors by sex hormones is dependent on sexual maturity [13]. In addition, opioid tone at the hypothalamic-pituitary level seems to change in an age-dependent manner. Indeed, in healthy elderly men, opioid tone was lower than in young men, as demonstrated by a reduction in the LH pulse amplitude and the frequency of high-amplitude pulses after naltrexone administration [85].

\section{Clinical consequences}

Opioids can induce several hypogonadism-related signs and symptoms, including sexual dysfunction, mood impairment, fatigue, weight gain and osteoporosis [16-18, 86], and these are described in more detail in the following sections. Regardless of the origin of hypogonadism, signs and symptoms are dependent on the age at onset [87, 88]. In adults and aging men, sexual dysfunction is the most specific symptom associated with low testosterone [89-91]. The European Male Aging Study, a population-based survey of more than 3400 men across eight European centers, showed that low libido, reduced spontaneity and sex-related ED were specifically associated with decreased testosterone levels, whereas other hypogonadal symptoms (e.g., physical and psychological changes) were less specific [89]. Similar results have been more recently reported in a population of men consulting for sexual dysfunction [100]. Furthermore, a large body of evidence has demonstrated that, although sexual dysfunction is the most specific symptom of adultonset hypogonadism, central obesity may be both a cause and effect of hypogonadism [92, 93].

As well as opioids affecting testosterone levels, testosterone may also be involved in the regulation of endogenous opioid activity. In fact, androgen receptors are involved in the transcriptional regulation of the MOP receptor [94]. Therefore, in men treated with opioids, hypogonadism may manifest as poor control of pain and hyperalgesia, which can in turn cause sexual dysfunction and mood impairment.

Sexual function Testosterone regulates male sexual function at both a central and peripheral level [95], so the association between sexual dysfunction and OPIAD is not surprising. However, it is important to recognize that chronic pain can also negatively affect sexual function through its associated disabilities, physical limitations and psychological distress [96, 97]. In addition, opioids can modulate sexual behavior by acting on the hypothalamic nuclei in the medial preoptic area and the spinal cord [13]. Further evidence supporting the negative impact of the endogenous opioid system on sexual function is derived from data obtained in patients with non-organic ED. Jannini and his group, in Italy, produced compelling evidence that robustly substantiated the hypothesis of an LH-mediated, sex-induced, drive in testosterone production [98-100] They essentially found that restoring sexual activity in patients affected by ED led to recovery of an otherwise borderline low testosterone level. The testosterone level rise was independent of the type of ED therapy employed, but was closely related to the successful outcome of therapeutic intervention. Hence, they speculated that sexual inertia resets the reproductive axis to a lower level of activity, somehow inducing a secondary hypogonadism, characterized by reduced LH bioactivity [100]. Consequently, restoring sex restores sex hormones, including bioavailable LH and testosterone [98-100]. The increased tone of the endogenous opioid system is the working hypothesis used by these researchers to explain their findings [101, 102]. Accordingly, the same researchers reported that the administration of naltrexone therapy for 7-15 days significantly increased the rate of successful coitus compared with placebo in these men [103].

Despite this evidence, few studies using standardized methods have evaluated the presence of sexual dysfunction in men receiving long-term opioids. In addition, most studies evaluating the effect of opioids on sexual function have been conducted in people with addictive disorders, limiting the generalizability of their findings [13]. A large cross-sectional study in 11,327 men with back pain found that the long-term use of opioids was associated with increased use of phosphodiesterase type 5 inhibitors or TTh [104]. In addition, patients prescribed a daily opioid dosage of at least $120 \mathrm{mg}$ morphine equivalents reported higher use of medication for ED compared with those receiving lower opioid doses [104]. A study of 120 men with CNCP, who had been receiving opioids for at least 12 months, found that $78 \%$ reported sexual dysfunction according to the International Index of Erectile Function (IIEF) score [70]. In most of these patients (69\%), the sexual dysfunction was severe [96]. In this study, $19 \%$ of patients had OPIAD, defined as a total testosterone level $<10.4 \mathrm{nmol} / \mathrm{L}$, and IIEF scores were significantly lower in those with OPIAD than in eugonadal men [70]. IIEF scores were worse in patients receiving oxycodone than other opioids [70], consistent with its more marked effect in reducing testosterone levels [45]. In other comparative studies of OPIAD and sexual dysfunction, buprenorphine (a partial $\mu$-opioid agonist used for opioid dependence) caused less marked reduction of testosterone levels and a lower incidence of sexual dysfunction, compared with methadone 
[105]. Standards have not been established for monitoring and treating OPIAD patients. However, according to the literature and expert opinion, patients who use opioids at doses higher than $100 \mathrm{mg}$ of morphine equivalents per day should be monitored for the development of hypogonadism [86].

Mood The association between $\mathrm{CNCP}$, depression and reduced quality of life is well documented [106]. In a large national sample of patients prescribed opioids for CNCP in Australia $(n=1418), 61 \%$ had ever experienced depression, and $66 \%$ of those patients reported depressive symptoms in the previous 12 months [107]. Among those who had reported lifetime depression, $48 \%$ developed depression after the onset of pain and the initiation of opioid medications. Several reports have also documented a dose- and duration-dependent association between chronic opioid treatment and new-onset depression [106]. One possible reason for this association is a reduction in testosterone levels caused by opioid administration [108, 109], with OPIAD contributing to the development of depression in patients with CNCP. However, the relationship between low testosterone levels and the incidence of clinical depression is still unclear, as is the potential benefit of TTh in men with depression or OPIAD [109].

Bone Osteopenia and osteoporosis are well-known consequences of male hypogonadism [110]. Osteopenia has been reported in 50\% of men treated with opioids for CNCP [55], and epidemiological studies have shown that opioid treatment is associated with a 50-60\% increase in the risk of osteoporotic fractures [86, 111]. Patients older than 60 years, who use opioids equivalent to $50 \mathrm{mg} /$ day or higher, have a $10 \%$ fracture rate per year, with a twofold higher risk than patients not using opioids [112]. Besides OPIAD, other factors may explain the relationship between opioid use and osteoporotic fractures. Opioids have a direct effect on bone formation by impairing osteoblastic activity via MOP receptors [86, 111]. In animal models, tramadol, which has lower affinity for the MOP receptor than morphine or fentanyl, is also associated with a lower incidence of osteoporosis than these agents [13]. The incidence of fractures may also be affected by the CNS effects of opioids, such as dizziness and sedation, which can play an important role in opioid-related falls [86].

Body composition and cardiovascular risk Several epidemiological studies have documented an association between CNCP, opioid use and obesity $[113,114]$. The reasons of this association are multifactorial. Physical limitations and depression related to CNCP may reduce energy expenditure and increase food intake [113, 114]. Conversely, opioids can modulate eating behavior [115]; as such, the combination therapy of naltrexone and bupropion has been approved for the treatment of obesity [115]. In addition, OPIAD can contribute to opioid-induced obesity. Observational studies have documented a close association between hypogonadism in adulthood and obesity or metabolic diseases [78, 92], partially restored by TTh [76, 116-118].

A possible relationship between low testosterone and increased cardiovascular risk has also been suggested [119-121]. However, it is not clear whether low testosterone in aging men plays a direct pathogenic role in cardiovascular disease, is a marker of poor health, or even a protective mechanism, turning off testosterone-dependent functions (such as reproduction and/or physical and sexual activity) when cardiovascular function is impaired [122, 123]. A large UK general practice research database found an increased risk of myocardial infarction in 1.7 million patients with at least one prescription for an opioid to treat CNCP between 1990 and 2008, especially in patients treated with morphine, meperidine and polytherapy [124]. The possible contribution of OPIAD was not investigated in this study.

\section{Management of opioid-induced androgen deficiency}

OPIAD is a reversible condition, and opioid withdrawal may normalize testosterone levels within 1 month in subjects with heroin addiction [125]. Similar data are not available in men with CNCP, but discontinuing an opioid molecule with lower effect on the HPG axis may be an option for symptomatic men with reduced testosterone levels. If discontinuing opioids is mandatory, non-opioid treatment should be considered for managing chronic pain in these patients. According to current guidelines, if pain relief with nonopioids is inadequate or patients are unable to discontinue opioid treatment, TTh should be considered [126-128]. A limited number of studies have evaluated the effects of TTh in men with OPIAD (Table 3) [129-133]. In the only randomized controlled trial available, TTh reduced mechanical hyperalgesia and improved sexual desire and overall quality of life [130]. The improvement of sexual function and pain relief after TTh was confirmed in other prospective and retrospective observational trials [129, 131-133]. The effects of TTh observed in men with OPIAD are consistent with the effects observed in the general population [109, 119, 134]. There is no general agreement among different societies on the ideal minimum levels of total testosterone for initiating TTh; the International Society for Sexual Medicine and the Endocrine Society have defined a minimum testosterone level of $12 \mathrm{nmol} / \mathrm{L}$ and $9.4 \mathrm{nmol} / \mathrm{L}$, respectively, [126, 128]. Meta-analyses have shown that TTh improves all aspects of sexual function when the total testosterone level is below $12 \mathrm{nmol} / \mathrm{L}(3.5 \mathrm{ng} / \mathrm{mL})[134,135]$. Similar beneficial effects of TTh have been observed for other outcomes, such as body composition (central adiposity, lean body mass) and glycometabolic parameters $[109,119]$. 


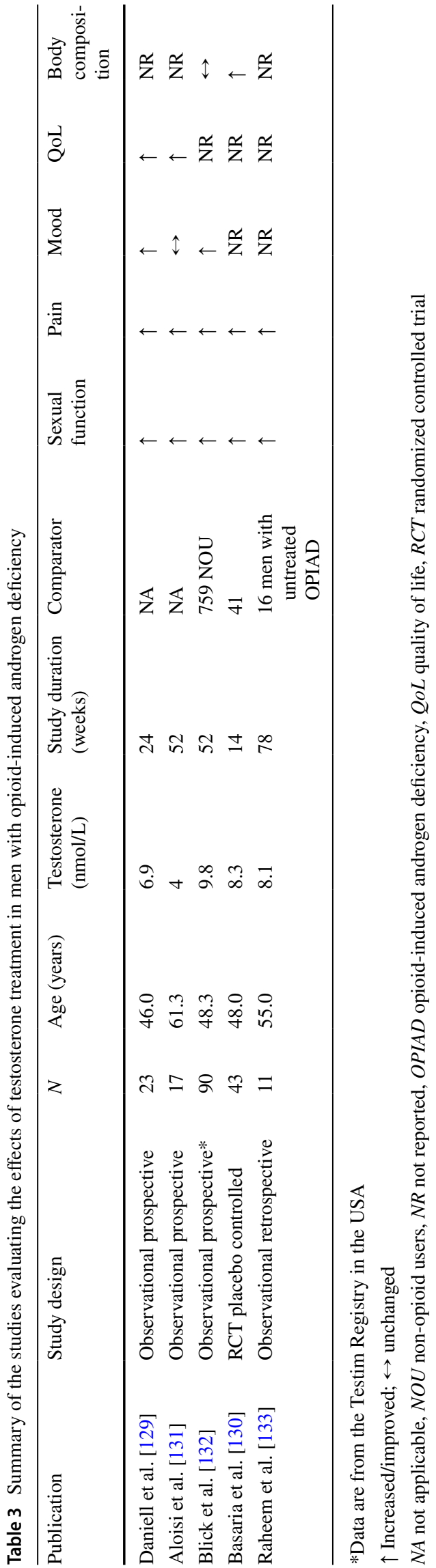

The effects of available testosterone preparations have been previously reviewed $[109,136]$. In summary, transdermal gel preparations, as well as long-acting injectable testosterone undecanoate, should be preferred over older short-acting injectable or oral testosterone formulations due to their better efficacy and safety profiles [109, 136, 137]. Side-by-side comparisons of different testosterone products are lacking and the choice of testosterone preparation should be discussed with the patient and the final decision based on the clinical situation.

\section{Conclusions}

OPIAD is a common AE of opioid treatment in men with CNCP. The presence of OPIAD can negatively affect pain relief and impair sexual function, mood and overall quality of life. However, it is important to recognize that testosterone levels in men progressively decrease as a function of age and comorbidities, which are common in patients with CNCP. Therefore, physicians should consider measuring testosterone levels in all men, before prescribing opioid treatment, and selecting opioids with a lower MOP affinity. In symptomatic patients with OPIAD, if opioid discontinuation is unlikely, TTh may be initiated; however, this decision should be discussed with the patient, emphasizing that, although there is some evidence to support positive shortterm outcomes, the long-term effect of TTh in men with OPIAD is unknown.

Acknowledgements Medical writing assistance with the editing of the manuscript was provided by Mimi Chan, $\mathrm{PhD}$, of Springer Healthcare Communications, with funding provided by Kyowa Kirin, Italy.

Funding Kyowa Kirin, Italy, provided non-conditional support to the writing of this manuscript.

\section{Compliance with ethical standards}

Conflict of interest FC and DB served as consultants and speakers for Grunenthal. GC served as speaker for Bayer and MM served as consultant and speaker for Bayer and Kyowa Kirin.

Ethical approval This article does not contain any studies with human participants or animals performed by any of the authors.

Informed consent Not applicable.

Open Access This article is distributed under the terms of the Creative Commons Attribution 4.0 International License (http://creativeco mmons.org/licenses/by/4.0/), which permits unrestricted use, distribution, and reproduction in any medium, provided you give appropriate credit to the original author(s) and the source, provide a link to the Creative Commons license, and indicate if changes were made. 


\section{References}

1. Phillips CJ (2009) The cost and burden of chronic pain. Rev Pain $3(1): 2-5$

2. Kress HG, Aldington D, Alon E et al (2015) A holistic approach to chronic pain management that involves all stakeholders: change is needed. Curr Med Res Opin 31(9):1743-1754

3. Kennedy J, Roll JM, Schraudner T et al (2014) Prevalence of persistent pain in the US adult population: new data from the 2010 national health interview survey. J Pain 15(10):979-984

4. Coluzzi F (2017) "I am in pain": is it really the magic formula to open the door of opioid abuse? Minerva Anestesiol 83(12):1332-1333

5. Kress HG, Ahlbeck K, Aldington D et al (2014) Managing chronic pain in elderly patients requires a change of approach. Curr Med Res Opin 30(6):1153-1164

6. Dowell D, Haegerich TM, Chou R (2016) CDC Guideline for Prescribing Opioids for Chronic Pain-United States, 2016. JAMA 315(15):1624-1645

7. Ambrosio F, Finco G, Mattia C et al (2006) SIAARTI chronic non-cancer pain study group. Minerva Anestesiol 72:80-859

8. Chou R, Fanciullo GJ, Fine PG et al (2009) Clinical guidelines for the use of chronic opioid therapy in chronic noncancer pain. J Pain 10(2):113-30. e22

9. Manchikanti L, Abdi S, Atluri S et al (2012) American Society of Interventional Pain Physicians (ASIPP) guidelines for responsible opioid prescribing in chronic non-cancer pain: part 2-guidance. Pain Phys 15(3 Suppl):S67-S116

10. Mattia C, Di Bussolo E, Coluzzi F (2012) Non-analgesic effects of opioids: the interaction of opioids with bone and joints. Curr Pharm Des 18(37):6005-6009

11. Coluzzi F, Rocco A, Mandatori I et al (2012) Non-analgesic effects of opioids: opioid-induced nausea and vomiting: mechanisms and strategies for their limitation. Curr Pharm Design. 18(37):6043-6052

12. Kumar L, Barker C, Emmanuel A (2014) Opioid-induced constipation: pathophysiology, clinical consequences, and management. Gastroent Res Pract 2014:141737

13. Vuong C, Van Uum SH, O'dell LE et al (2009) The effects of opioids and opioid analogs on animal and human endocrine systems. Endocr Rev 31(1):98-132

14. Corona G, Vignozzi L, Sforza A et al (2013) Risks and benefits of late onset hypogonadism treatment: an expert opinion. World J Men's Health 31(2):103-125

15. Corona G, Maseroli E, Rastrelli G et al (2016) Is late-onset hypogonadotropic hypogonadism a specific age-dependent disease, or merely an epiphenomenon caused by accumulating diseaseburden? Minerva Endocrinol 41(2):196-210

16. Brennan MJ (2013) The effect of opioid therapy on endocrine function. Am J Med 126(3):S12-S18

17. Aloisi AM, Aurilio C, Bachiocco V et al (2009) Endocrine consequences of opioid therapy. Psychoneuroendocrino 34(Suppl 1):S162-S168

18. Smith HS, Elliott JA (2012) Opioid-induced androgen deficiency (OPIAD). Pain Phys 15(3 Suppl):145-156

19. Grossmann M, Matsumoto AM (2017) A perspective on middleaged and older men with functional hypogonadism: focus on holistic management. J Clin Endocr Metab 102(3):1067-1075

20. Pathan H, Williams J (2012) Basic opioid pharmacology: an update. Br J Pain 6(1):11-16

21. Stein C, Schäfer M, Machelska H (2003) Attacking pain at its source: new perspectives on opioids. Nat Med 9(8):1003
22. Corbett AD, Henderson G, McKnight AT et al (2006) 75 years of opioid research: the exciting but vain quest for the Holy Grail. Br J Pharmacol 147(S1):S153-S162

23. Schwarzer C (2009) 30 years of dynorphins-new insights on their functions in neuropsychiatric diseases. Pharmacol Ther 123(3):353-370

24. McDonald J, Lambert D (2005) Opioid receptors. Contin Educ Anaesth Crit Care Pain 5(1):22-25

25. Coluzzi F, Taylor R Jr, Pergolizzi JV Jr et al (2016) Good clinical practice guide for opioids in pain management: the three Tstitration (trial), tweaking (tailoring), transition (tapering). Braz J Anesthesiol 66(3):310-317

26. Daubresse M, Chang HY, Yu Y et al (2013) Ambulatory diagnosis and treatment of nonmalignant pain in the United States, 2000-2010. Med Care 51(10):870-878

27. Lurcott G (1998) The effects of the genetic absence and inhibition of CYP2D6 on the metabolism of codeine and its derivatives, hydrocodone and oxycodone. Anesth Prog 45(4):154

28. Mattia C, Coluzzi F (2015) A look inside the association codeineparacetamol: clinical pharmacology supports analgesic efficacy. Eur Rev Med Pharmacol Sci 19(3):507-516

29. Dayer P, Collart L, Desmeules J (1994) The pharmacology of tramadol. Drugs 47(1):3-7

30. Mattia C, Coluzzi F (2005) Tramadol. Focus on musculoskeletal and neuropathic pain. Minerva Anestesiol 71(10):565-584

31. Mattia C, Coluzzi F (2006) Once-daily tramadol in rheumatological pain. Expert Opin Pharmacother 7(13):1811-1823

32. Coluzzi F, Mattia C (2007) Chronic non-cancer pain: focus on once-daily tramadol formulations. Ther Clin Risk Manag 3(5):819-829

33. Mattia C, Coluzzi F, Sarzi Puttini P et al (2008) Paracetamol/ Tramadol association: the easy solution for mild-moderate pain. Minerva Med 99(4):369-390

34. Trescot AM, Datta S, Lee M et al (2008) Opioid pharmacology. Pain Physician 11(2 Suppl):S133-S153

35. Ghelardini C, Mannelli LDC, Bianchi E (2015) The pharmacological basis of opioids. Clin Cases Miner Bone Metabol 12(3): 219

36. Oldendorf WH (1974) Lipid solubility and drug penetration of the blood brain barrier. Proc Soc Exp Biol Med 147(3):813-816

37. Schaefer CP, Tome ME, Davis TP (2017) The opioid epidemic: a central role for the blood brain barrier in opioid analgesia and abuse. Fluids Barriers CNS 14(1):32

38. Coluzzi F, Mattia C (2005) Oxycodone. Pharmacological profile and clinical data in chronic pain management. Minerva Anestesiol 71(7-8):451-460

39. Nielsen CK, Ross FB, Lotfipour S et al (2007) Oxycodone and morphine have distinctly different pharmacological profiles: radioligand binding and behavioural studies in two rat models of neuropathic pain. Pain 132(3):289-300

40. Kim ES (2017) Oxycodone/naloxone prolonged release: a review in severe chronic pain. Clin Drug Investig 37(12):1191-1201

41. Baron R, Jansen JP, Binder A et al (2016) Tolerability, safety, and quality of life with tapentadol prolonged release (PR) compared with oxycodone/naloxone PR in patients with severe chronic low back pain with a neuropathic component: a randomized, controlled, open-label, phase 3b/4 trial. Pain Pract 16(5):600-619

42. Coluzzi F, Mattia C (2010) OROS(R) hydromorphone in chronic pain management: when drug delivery technology matches clinical needs. Minerva Anestesiol 76(12):1072-1084

43. Scholz J, Steinfath M, Schulz M (1996) Clinical pharmacokinetics of alfentanil, fentanyl and sufentanil. Clin Pharmacokinet 31(4):275-292 
44. Kornick CA, Santiago-Palma J, Moryl N et al (2003) Benefit-risk assessment of transdermal fentanyl for the treatment of chronic pain. Drug Saf 26(13):951-973

45. Rubinstein AL, Carpenter DM (2017) Association between commonly prescribed opioids and androgen deficiency in men: a retrospective cohort analysis. Pain Med 18(4):637-644

46. Coluzzi F, Fornasari D, Pergolizzi J et al (2017) From acute to chronic pain: tapentadol in the progressive stages of this disease entity. Eur Rev Med Pharmacol Sci 21(7):1672-1683

47. Pergolizzi JV Jr, Breve F, Taylor R Jr et al (2017) Considering tapentadol as a first-line analgesic: 14 questions. Pain Manag 7(4):331-339

48. Billeci D, Coluzzi F (2017) Tapentadol extended release for the management of chronic neck pain. J Pain Res 10:495-505

49. Pergolizzi JV Jr, Taylor R Jr, LeQuang JA et al (2018) Tapentadol extended release in the treatment of severe chronic low back pain and osteoarthritis pain. Pain Ther 7:37-57

50. Vadivelu N, Kai A, Maslin B et al (2015) Tapentadol extended release in the management of peripheral diabetic neuropathic pain. Ther Clin Risk Manag 11:95-105

51. Coluzzi F, Ruggeri M (2014) Clinical and economic evaluation of tapentadol extended release and oxycodone/naloxone extended release in comparison with controlled release oxycodone in musculoskeletal pain. Curr Med Res Opin 30(6):1139-1151

52. Ide S, Minami M, Satoh M et al (2004) Buprenorphine antinociception is abolished, but naloxone-sensitive reward is retained, in $\mu$-opioid receptor knockout mice. Neuropsychopharmacology 29(9): 1656

53. Pergolizzi JV, Coluzzi F, Taylor R (2018) Transdermal buprenorphine for moderate chronic noncancer pain syndromes. Expert Rev Neurother 18(5):359-369

54. Coluzzi F, Bifulco F, Cuomo A et al (2017) The challenge of perioperative pain management in opioid-tolerant patients. Ther Clin Risk Manag 13:1163-1173

55. Fraser LA, Morrison D, Morley-Forster P et al (2009) Oral opioids for chronic non-cancer pain: higher prevalence of hypogonadism in men than in women. Exp Clin Endocrinol Diabetes 117(1):38-43

56. Azizi F, Vagenakis AG, Longcope C et al (1973) Decreased serum testosterone concentration in male heroin and methadone addicts. Steroids 22(4):467-472

57. Cicero TJ, Bell RD, Wiest WG et al (1975) Function of the male sex organs in heroin and methadone users. N Engl J Med 292(17):882-887

58. Bawor M, Bami H, Dennis BB et al (2015) Testosterone suppression in opioid users: a systematic review and meta-analysis. Drug Alcohol Depend 01(149):1-9

59. Hahn JA, Samet JH (2010) Alcohol and HIV disease progression: weighing the evidence. Curr HIV-AIDS Rep 7(4):226-233

60. Drobnis EZ, Nangia AK (2017) Antivirals and male reproduction. Adv Exp Med Biol 1034:163-178

61. Rochira V, Guaraldi G (2014) Hypogonadism in the HIV-infected man. Endocrin Metab Clin 43(3):709-730

62. Abs R, Verhelst J, Maeyaert J et al (2000) Endocrine consequences of long-term intrathecal administration of opioids. J Clin Endocr Metab 85(6):2215-2222

63. Finch PM, Roberts LJ, Price L et al (2000) Hypogonadism in patients treated with intrathecal morphine. Clin J Pain 16(3):251-254

64. Daniell HW (2002) Hypogonadism in men consuming sustainedaction oral opioids. J Pain 3(5):377-384

65. Roberts LJ, Finch PM, Pullan PT et al (2002) Sex hormone suppression by intrathecal opioids: a prospective study. Clin J Pain 18(3):144-148
66. Rajagopal A, Vassilopoulou-Sellin R, Palmer JL et al (2003) Hypogonadism and sexual dysfunction in male cancer survivors receiving chronic opioid therapy. J Pain Symptom Manag 26(5):1055-1061

67. Dudley U, Duarte RV (2013) Prevalence and influence of diagnostic criteria in the assessment of hypogonadism in intrathecal opioid therapy patients. Pain Physician 16:9-14

68. Rubinstein AL, Carpenter DM, Minkoff JR (2013) Hypogonadism in men with chronic pain linked to the use of long-acting rather than short-acting opioids. Clin J Pain 29(10):840-845

69. Rubinstein A, Carpenter DM (2014) Elucidating risk factors for androgen deficiency associated with daily opioid use. Am J Med 127(12):1195-1201

70. Ajo R, Segura A, Inda MM et al (2016) Opioids increase sexual dysfunction in patients with non-cancer pain. J Sex Med 13(9):1377-1386

71. Cepeda MS, Zhu V, Vorsanger G et al (2015) Effect of opioids on testosterone levels: cross-sectional study using NHANES. Pain Med 16(12):2235-2242

72. Kim CH, Garcia R, Stover J et al (2014) Androgen deficiency in long-term intrathecal opioid administration. Pain Physician 17(4):543-548

73. Elliott JA, Horton E, Fibuch EE (2011) The endocrine effects of long-term oral opioid therapy: a case report and review of the literature. J Opioid Manag 7(2):145-154

74. Eichenbaum G, Gohler K, Etropolski M et al (2015) Does tapentadol affect sex hormone concentrations differently from morphine and oxycodone? An initial assessment and possible implications for opioid-induced androgen deficiency. J Opioid Manag 11(3):211-227

75. Corona G, Vignozzi L, Sforza A et al (2015) Obesity and lateonset hypogonadism. Mol Cell Endocrinol 418:120-133

76. Corona G, Giagulli VA, Maseroli E et al (2016) Testosterone supplementation and body composition: results from a meta-analysis of observational studies. J Endocrinol Invest 39(9):967-981

77. Corona G, Giorda C, Cucinotta D et al (2013) The SUBITODE study: sexual dysfunction in newly diagnosed type 2 diabetes male patients. J Endocrinol Invest 36(10):864-868

78. Kelly D, Jones T (2015) Testosterone and obesity. Obes Rev 16(7):581-606

79. Wiesner J, Koenig J, Krulich L et al (1984) Site of action for $\beta$-endorphin-induced changes in plasma luteinizing hormone and prolactin in the ovariectomized rat. Life Sci 34(15):1463-1473

80. Li S, Pelletier G (1993) Opioid regulation of gonadotropinreleasing hormone gene expression in the male rat brain as studied by in situ hybridization. NeuroReport 4(3):331-333

81. Gabriel SM, Simpkins JW, Kalra SP et al (1985) Chronic morphine treatment induces hypersensitivity to testosterone-negative feedback in castrated male rats. Neuroendocrinology 40(1):39-44

82. Aloisi AM, Ceccarelli I, Fiorenzani P et al (2010) Aromatase and 5-alpha reductase gene expression: modulation by pain and morphine treatment in male rats. Mol Pain 6(1):69

83. Rosa M, de la Raymond E, Hennessey M, James V (1996) Hypogonadism and methadone: hypothalamic hypogonadism after long-term use of high-dose methadone. Endocr Pract 2(1):4-7

84. Petraglia F, Bernasconi S, Iughetti L et al (1986) Naloxoneinduced luteinizing hormone secretion in normal, precocious, and delayed puberty. J Clin Endocrinol Metab 63(5):1112-1116

85. Vermeulen A, Deslypere JP, Kaufman JM (1989) Influence of antiopioids on luteinizing hormone pulsatility in aging men. $\mathrm{J}$ Clin Endocrinol Metab 68(1):68-72

86. Coluzzi F, Pergolizzi J, Raffa RB et al (2015) The unsolved case of "bone-impairing analgesics": the endocrine effects of opioids on bone metabolism. Ther Clin Risk Manag 11:515-523 
87. Rastrelli G, Giovannini L, Calogero A et al (2016) Predictors and clinical consequences of starting androgen therapy in men with low testosterone: results from the SIAMO-NOI registry. J Endocrinol Invest 39(6):695-708

88. Corona G, Rastrelli G, Vignozzi L et al (2012) Emerging medication for the treatment of male hypogonadism. Expert Opin Emerg Dr 17(2):239-259

89. Wu FC, Tajar A, Beynon JM et al (2010) Identification of lateonset hypogonadism in middle-aged and elderly men. N Engl $\mathbf{J}$ Med 363(2):123-135

90. Corona G, Bianchini S, Sforza A et al (2015) Hypogonadism as a possible link between metabolic diseases and erectile dysfunction in aging men. Hormones (Athens) 14(4):569-578

91. Maseroli E, Corona G, Rastrelli G et al (2015) Prevalence of endocrine and metabolic disorders in subjects with erectile dysfunction: a comparative study. J Sex Med 12(4):956-965

92. Lamm S, Chidakel A, Bansal R (2016) Obesity and hypogonadism. Urol Clin 43(2):239-245

93. Isidori AM, Balercia G, Calogero A et al (2015) Outcomes of androgen replacement therapy in adult male hypogonadism: recommendations from the Italian society of endocrinology. J Endocrinol Invest 38(1):103-112

94. Lee KS, Zhang Y, Asgar J et al (2016) Androgen receptor transcriptionally regulates $\mu$-opioid receptor expression in rat trigeminal ganglia. Neuroscience 331:52-61

95. Corona G, Isidori AM, Aversa A et al (2016) Endocrinologic control of men's sexual desire and arousal/erection. J Sex Med 13(3):317-337

96. Ambler N, de Williams AC, Hill P et al (2001) Sexual difficulties of chronic pain patients. Clin J Pain 17(2):138-145

97. Tajar A, O'Neill TW, Lee DM et al (2011) The effect of musculoskeletal pain on sexual function in middle-aged and elderly European men: results from the European male ageing study. J Rheumatol 38(2):370-377

98. Carosa E, Benvenga S, Trimarchi F et al (2002) Sexual inactivity results in reversible reduction of LH bioavailability. Int J Impot Res 14(2):93-99 (Discussion 100)

99. Carosa E, Martini P, Brandetti F et al (2004) Type V phosphodiesterase inhibitor treatments for erectile dysfunction increase testosterone levels. Clin Endocrinol 61(3):382-386

100. Jannini EA, Screponi E, Carosa E et al (1999) Lack of sexual activity from erectile dysfunction is associated with a reversible reduction in serum testosterone. Int J Androl 22(6):385-392

101. Fabbri A, Jannini EA, Gnessi L et al (1989) Neuroendocrine control of male reproductive function. The opioid system as a model of control at multiple sites. J Steroid Biochem 32(1B):145-150

102. Fabbri A, Jannini EA, Ulisse S et al (1988) Low serum bioactive luteinizing hormone in nonorganic male impotence: possible relationship with altered gonadotropin-releasing hormone pulsatility. J Clin Endocrinol Metab 67(5):867-875

103. Fabbri A, Jannini EA, Gnessi L et al (1989) Endorphins in male impotence: evidence for naltrexone stimulation of erectile activity in patient therapy. Psychoneuroendocrinology 14(1-2):103-111

104. Deyo RA, Smith DH, Johnson ES et al (2013) Prescription opioids for back pain and use of medications for erectile dysfunction. Spine 38(11):909

105. Bliesener N, Albrecht S, Schwager A et al (2005) Plasma testosterone and sexual function in men receiving buprenorphine maintenance for opioid dependence. J Clin Endocri Metab 90(1):203-206

106. Davis MP, Mehta $Z$ (2016) Opioids and chronic pain: where is the balance? Curr Oncol Rep 18(12):71

107. Smith K, Mattick RP, Bruno R et al (2015) Factors associated with the development of depression in chronic non-cancer pain patients following the onset of opioid treatment for pain. J Affect Disord 184:72-80

108. Smith JB, Rosen J, Colbert A (2018) Low serum testosterone in outpatient psychiatry clinics: addressing challenges to the screening and treatment of hypogonadism. Sex Med Rev 6(1):69-76

109. Rastrelli G, Maggi M, Corona G (2018) Pharmacological management of late-onset hypogonadism. Expert Rev Clin Pharmacol 11:439-458

110. Rochira V, Antonio L, Vanderschueren D (2018) EAA clinical guideline on management of bone health in the andrological outpatient clinic. Andrology 6(2):272-285

111. Vestergaard P, Rejnmark L, Mosekilde L (2006) Fracture risk associated with the use of morphine and opiates. J Intern Med 260(1):76-87

112. Saunders KW, Dunn KM, Merrill JO et al (2010) Relationship of opioid use and dosage levels to fractures in older chronic pain patients. J Gen Intern Med 25(4):310-315

113. Højsted J, Ekholm O, Kurita GP et al (2013) Addictive behaviors related to opioid use for chronic pain: a population-based study. Pain 154(12):2677-2683

114. Birke H, Kurita G, Sjøgren P et al (2016) Chronic non-cancer pain and the epidemic prescription of opioids in the Danish population: trends from 2000 to 2013. Acta Anaesth Scand 60(5):623-633

115. Nogueiras R, Romero-Picó A, Vazquez MJ et al (2012) The opioid system and food intake: homeostatic and hedonic mechanisms. Obes Facts 5(2):196-207

116. Corona G, Giagulli V, Maseroli E et al (2015) Therapy of endocrine disease: testosterone supplementation and body composition: results from a meta-analysis study. Eur J Endocrinol 174:R99-R116

117. Corona G, Maseroli E, Maggi M (2014) Injectable testosterone undecanoate for the treatment of hypogonadism. Expert Opin Pharmacol 15(13): 1903-1926

118. Francomano D, Bruzziches R, Barbaro G et al (2014) Effects of testosterone undecanoate replacement and withdrawal on cardio-metabolic, hormonal and body composition outcomes in severely obese hypogonadal men: a pilot study. J Endocrinol Invest 37(4):401-411

119. Corona G, Sforza A, Maggi M (2017) Testosterone replacement therapy: long-term safety and efficacy. World J Mens Health 35(2):65-76

120. Corona G, Dicuio M, Rastrelli G et al (2017) Testosterone treatment and cardiovascular and venous thromboembolism risk: what is 'new'? J Invest Med 65:964-973

121. Anawalt BD, Yeap BB (2018) Conclusions about testosterone therapy and cardiovascular risk. Asian J Androl 20(2):152

122. Corona G, Rastrelli G, Maseroli E et al (2014) Low testosterone syndrome protects subjects with high cardiovascular risk burden from major adverse cardiovascular events. Andrology 2(5):741-747

123. Corona G, Rastrelli G, Monami M et al (2011) Body mass index regulates hypogonadism-associated CV risk: results from a cohort of subjects with erectile dysfunction. J Sex Med 8(7):2098-2105

124. Li L, Setoguchi S, Cabral H et al (2013) Opioid use for noncancer pain and risk of myocardial infarction amongst adults. J Intern Med 273(5):511-526

125. Mendelson JH, Mendelson JE, Patch VD (1975) Plasma testosterone levels in heroin addiction and during methadone maintenance. J Pharmacol Exp Ther 192(1):211-217

126. Khera M, Adaikan G, Buvat J et al (2016) Diagnosis and treatment of testosterone deficiency: recommendations from the Fourth International Consultation for Sexual Medicine (ICSM 2015). J Sex Med 13(12):1787-1804 
127. Yeap BB, Grossmann M, McLachlan RI et al (2016) Endocrine Society of Australia position statement on male hypogonadism (part 1): assessment and indications for testosterone therapy. Med J Aust 205(4):173-178

128. Bhasin S, Brito JP, Cunningham GR et al (2018) Testosterone therapy in men with hypogonadism: An Endocrine Society Clinical Practice Guideline. J Clin Endocrinol Metab 103:1715-1744

129. Daniell HW, Lentz R, Mazer NA (2006) Open-label pilot study of testosterone patch therapy in men with opioid-induced androgen deficiency. J Pain 7(3):200-210

130. Basaria S, Travison TG, Alford D et al (2015) Effects of testosterone replacement in men with opioid-induced androgen deficiency: a randomized controlled trial. Pain 156(2):280-288

131. Aloisi AM, Ceccarelli I, Carlucci M et al (2011) Hormone replacement therapy in morphine-induced hypogonadic male chronic pain patients. Reprod Biol Endocrinol 9(1):26

132. Blick G, Khera M, Bhattacharya RK et al (2012) Testosterone replacement therapy outcomes among opioid users: the Testim Registry in the United States (TRiUS). Pain Med 13(5):688-698
133. Raheem OA, Patel SH, Sisul D et al (2017) The role of testosterone supplemental therapy in opioid-induced hypogonadism: a retrospective pilot analysis. Am J Mens Health 11(4):1208-1213

134. Corona G, Rastrelli G, Morgentaler A et al (2017) Meta-analysis of results of testosterone therapy on sexual function based on International Index of Erectile Function Scores. Eur Urol 72(6):1000-1011

135. Corona G, Isidori AM, Buvat J et al (2014) Testosterone supplementation and sexual function: a meta-analysis study. J Sex Med 11(6):1577-1592

136. Corona G, Ratrelli G, Maggi M (2015) The pharmacotherapy of male hypogonadism besides androgens. Expert Opin Pharmacol 16(3):369-387

137. Corona G, Rastrelli G, Reisman Y et al (2018) The safety of available treatments of male hypogonadism in organic and functional hypogonadism. Expert Opin Drug Saf 17:277-292 